\title{
Protection by free oxygen radical scavenging enzymes against glucose-induced embryonic malformations in vitro ${ }^{*}$
}

\author{
U.J.Eriksson and L.A.H.Borg \\ Department of Medical Cell Biology, University of Uppsala, Uppsala, Sweden
}

\begin{abstract}
Summary. This study addresses the possibility that the teratogenic effects of a diabetic pregnancy are associated with increased embryonic activities of free oxygen radicals. Rat embryos were cultured in $50 \mathrm{mmol} / 1$ glucose for $48 \mathrm{~h}$ and subsequently showed pronounced growth retardation and severe malformations. The enzyme inducer citiolone and the free oxygen radical scavenging enzymes superoxide dismutase, catalase and glutathione peroxidase protected against the disturbed growth and development of the embryos at $50 \mathrm{mmol} / \mathrm{lglucose}$ when added to the culture media. Enzymatic measurements indicated that citiolone induced an increased activity of superoxide dismutase in the embryonic tissues and that the added enzymes were taken up by both the
\end{abstract}

yolk sac and the embryo proper. The protection against embryonic maldevelopment was thus conferred by agents that increased the free oxygen radical scavenging capacity of the embryonic tissues. The results suggest that a high glucose concentration in vitro causes embryonic dysmorphogenesis by generation of free oxygen radicals. An enhanced production of such radicals in embryonic tissues may be directly related to the increased risk of congenital malformations in diabetic pregnancy.

Key words: Diabetic pregnancy, congenital malformation, free oxygen radicals, rat, whole embryo culture, citiolone, superoxide dismutase, catalase, glutathione peroxidase.
For a diabetic woman the risk of bearing a malformed child is 2-3 times higher than for a normal woman [1], and compared with normal pregnancies a greater proportion of the congenital malformations in diabetic pregnancies are lethal [2-4]. The exact pathogenesis of the malformations is at present unknown.

It has been suggested that complications of diabetes mellitus such as angiopathy, retinopathy, neuropathy and nephropathy result from an increased production of free oxygen radicals [5-7]. In this context, it is suggested that congenital malformations in diabetic pregnancy may be regarded as a type of complication of the maternal disease. Furthermore, short-time exposure of rat embryos to xanthine and xanthine oxidase immediately before culture in vitro causes altered embryonic development, suggesting a role for free oxygen radicals in disturbed embryogenesis [8]. Against this background a new approach towards the understanding of the dysmorphogenesis in diabetic pregnancy would be to investigate whether free oxygen radicals are involved in the teratogenic process. A direct coupling

* This study was presented in part at the 26th Annual Meeting of the European Association for the Study of Diabetes, Copenhagen, Denmark, 10-14 September 1990 between free radical generation in diabetic pregnancy and the induction of congenital malformations has, to our knowledge, not been proposed before.

In the present study, therefore, we subjected rat embryos to a teratogenic milieu in vitro, i.e. they were cultured in a high glucose concentration known to cause growth retardation and malformations [9-11]. The culture media were supplemented either with citiolone ( $\mathrm{N}$-acetylDL-homocysteine thiolactone), which is an inducer of oxygen radical scavenging enzymes [12, 13], or with superoxide dismutase, catalase or glutathione peroxidase. The effects exerted by the different additions to the culture medium on embryonic development were subsequently evaluated. A preliminary account of the results has been published previously [14].

\section{Materials and methods}

\section{Animals}

Embryos were obtained from females of an outbred strain of Sprague-Dawley rats, provided by a commercial breeder (ALAB, Sollentuna, Sweden) which were mated with males from a local out- 
bred Sprague-Dawley strain with an increased incidence of congenital malformations in diabetic pregnancy $[11,15]$. The rats were fed a commercial pelleted diet (R3; Ewos, Södertälje, Sweden) and had free access to food and tap water. They were maintained at an ambient temperature of $22^{\circ} \mathrm{C}$ with a $12 \mathrm{~h} \mathrm{light/dark}$ cycle. The light was turned on at 01.00 hours and off at 13.00 hours. Female and male rats were caged together during the dark periods. Conception was verified by the presence of sperm in a vaginal smear. The morning that conception was verified was designated gestational day 0 .

\section{Embryo culture}

Between 11.00 hours and 13.00 hours on gestational day 9 the pregnant rats were killed by cervical dislocation. The conceptuses were explanted, and culture of whole embryos was performed according to New [16]. The embryos, within their intact yolk sacs, were maintained in polypropylene tubes (Falcon 2070 ) in a roller incubator at $38^{\circ} \mathrm{C}$ and $60 \mathrm{rev} / \mathrm{min}$. Each tube contained $4-5$ conceptuses in $5 \mathrm{ml}$ culture medium consisting of $80 \%$ volume/volume $(\mathrm{v} / \mathrm{v})$ rat serum and $20 \%(\mathrm{v} / \mathrm{v})$ $0.9 \%$ weight/volume $(\mathrm{w} / \mathrm{v}) \mathrm{NaCl}$. The serum was centrifuged immediately after bleeding of the donors [17] and supplemented with sodium benzylpenicillinate and streptomycin to give a final concentration of $60 \mathrm{mg} / \mathrm{l}$ and $100 \mathrm{mg} / \mathrm{l}$, respectively. The serum was stored frozen and heat-inactivated at $56^{\circ} \mathrm{C}$ for $1 \mathrm{~h}$ immediately before use. The glucose concentration of culture media was adjusted to 10 or $50 \mathrm{mmol} / \mathrm{l}$ by the addition of a sterile solution of $1.67 \mathrm{~mol} / \mathrm{l} \mathrm{D}$-glucose. Citiolone (CIT; $\mathrm{N}$-acetyl-DL-homocysteine thiolactone), superoxide dismutase (SOD; E.C. 1.15.1.1), catalase (CAT; E.C. 1.11.1.6), and glutathione peroxidase (GPX; E.C. 1.11.1.9) were added to culture media from concentrated sterile stock solutions or suspensions in $0.9 \%(\mathrm{w} / \mathrm{v})$ $\mathrm{NaCl}$. The final concentrations were $0.5 \mathrm{mmol} / \mathrm{l}$ of $\mathrm{CIT}, 2.5 \mathrm{MU} / \mathrm{l}$ of SOD, $0.5 \mathrm{mkat} / \mathrm{l}$ of CAT, and $1.5 \mathrm{mkat} / \mathrm{l}$ of GPX. Unsupplemented, media had an endogenous activity of $2.5 \mathrm{kU} / \mathrm{lSOD}$, of $17 \mathrm{nkat} / \mathrm{lCAT}$ and of $40 \mu \mathrm{kat} / \mathrm{l} \mathrm{GPX}$. Both the endogenous and exogenous activities of SOD and CAT remained constant during culture, whereas the activity of GPX decreased by about $50 \%$ per $24 \mathrm{~h}$. At the start of culture, the tubes were gassed with $5 \% \mathrm{O}_{2}, 5 \% \mathrm{CO}_{2}$ and $90 \% \mathrm{~N}_{2}(\mathrm{v} / \mathrm{v} / \mathrm{v})$ and capped tightly. After $24 \mathrm{~h}$ the conceptuses were transferred to new culture tubes with fresh media as described above and gassed with $20 \% \mathrm{O}_{2}, 5 \% \mathrm{CO}_{2}$ and $75 \% \mathrm{~N}_{2}(\mathrm{v} / \mathrm{v} / \mathrm{v})$. The following morning (i.e. after a further $20 \mathrm{~h}$ of culture) the tubes were gassed with $40 \% \mathrm{O}_{2}, 5 \%$ $\mathrm{CO}_{2}$ and $55 \% \mathrm{~N}_{2}(\mathrm{v} / \mathrm{v} / \mathrm{v})$ for $10 \mathrm{~min}$ to obtain an appropriate oxygen tension for this stage of culture [18].

The tubes were harvested $4-6 \mathrm{~h}$ later, i.e. at a time-point corresponding to gestational day 11.7. The conceptuses were transferred to Petri dishes containing $0.9 \%(\mathrm{w} / \mathrm{v}) \mathrm{NaCl}$ and viewed in a stereo microscope at a magnification of 10-20 $\mathrm{x}$. The embryo proper and its yolk sac membrane were separated by gentle dissection and rinsed carefully for $10 \mathrm{~min}$. The crown rump length of each embryo was measured, and the number of somites was counted. The embryos were categorized as morphologically normal or showing minor or major malformations. Normal embryos exhibited an entirely correct body flexure and closure of both the anterior and posterior neural pore (Fig.1A). Embryos having a small malrotation or a delayed closure of a single neural pore were classified as being minor malformed (Fig. 1 B). A severe malrotation, an abnormally open neural tube or a cardiac hypertrophy was defined as a major malformation (Fig. 1C). An average malformational score was calculated for each experimental condition, where normal embryos and embryos with minor and major malformations were assigned individual scores of 0,1 and 10, respectively. The embryos were photographed in darkfield illumination using a Wild M3Z stereo microscope equipped with a MPS $45 / 51$ photoautomat (Wild, Heerbrugg, Switzerland).

Enzymatic activities and the protein and DNA content were determined separately in embryos and membranes. Tissue homogenates were prepared in ice-cold buffers using a ground-glass homogenizer (Kontes Glass Co., Vineland, UNJ, USA) of 2-ml capacity. One embryo or membrane was homogenized in $500 \mu \mathrm{l}$ of a $100 \mathrm{mmol} / 1 \mathrm{Na}_{2} \mathrm{HPO}_{4}-\mathrm{KH}_{2} \mathrm{PO}_{4}$ buffer of $\mathrm{pH} 7.8$, which contained $0.1 \mathrm{mmol} / 1$ EDTA (ethylenediaminetetraacetic acid), for determination of SOD, two embryos or membranes were homogenized in $500 \mu \mathrm{l}$ of a $25 \mathrm{mmol} / \mathrm{K} \mathrm{KH}_{2} \mathrm{PO}_{4}-\mathrm{NaOH}$ buffer of $\mathrm{pH} 7.0$ for determination of CAT, and two embryos or membranes were homogenized in $250 \mu \mathrm{l}$ of a $250 \mathrm{mmol} / 1 \mathrm{KH}_{2} \mathrm{PO}_{4}-\mathrm{NaOH}$ buffer of $\mathrm{pH} 7.0$ with $2.5 \mathrm{mmol} / \mathrm{LDTA}$ for determination of GPX.

\section{Determination of protein and DNA}

The protein content of the homogenates was determined by the method of Lowry et al. [19] using bovine serum albumin as a standard, and DNA was measured as described by Kissane and Robins [20] and Hinegardner [21].

\section{Measurement of enzyme activities}

Superoxide dismutase. The activity of SOD was measured by its inhibition of the chemiluminescence of luminol (5-amino-2,3-dihydro1,4-phthalazinedione), which was induced by superoxide anions produced by the action of xanthine oxidase (E.C. 1.1.3.22) on xanthine [22]. By the use of this method interference from other activites in the crude tissue homogenates could be avoided [23]. Portions $(25 \mu 1)$ of homogenates, blanks or appropriate standards were, in duplicate, mixed with $600 \mu \mathrm{l}$ of a medium consisting of $0.25 \mathrm{mmol} / \mathrm{l}$ xanthine, $1.0 \mathrm{mmol} / 1 \mathrm{luminol}$ and $0.1 \mathrm{mmol} / 1 \mathrm{EDTA}$ in a $50 \mathrm{mmol} / 1$ carbonate buffer, $\mathrm{pH} 10.1$, in small polystyrene test tubes at room temperature $\left(20^{\circ} \mathrm{C}\right)$. The light-emitting reaction was initiated by the addition of $40 \mu \mathrm{l}$ of a solution of $0.12 \mathrm{~g} / \mathrm{l}$ xanthine oxidase in carbonate buffer. The chemiluminescence was determined using a LKB-Wallac Luminometer 1250 (LKB-Wallac, Turku, Finland) connected to a poten-
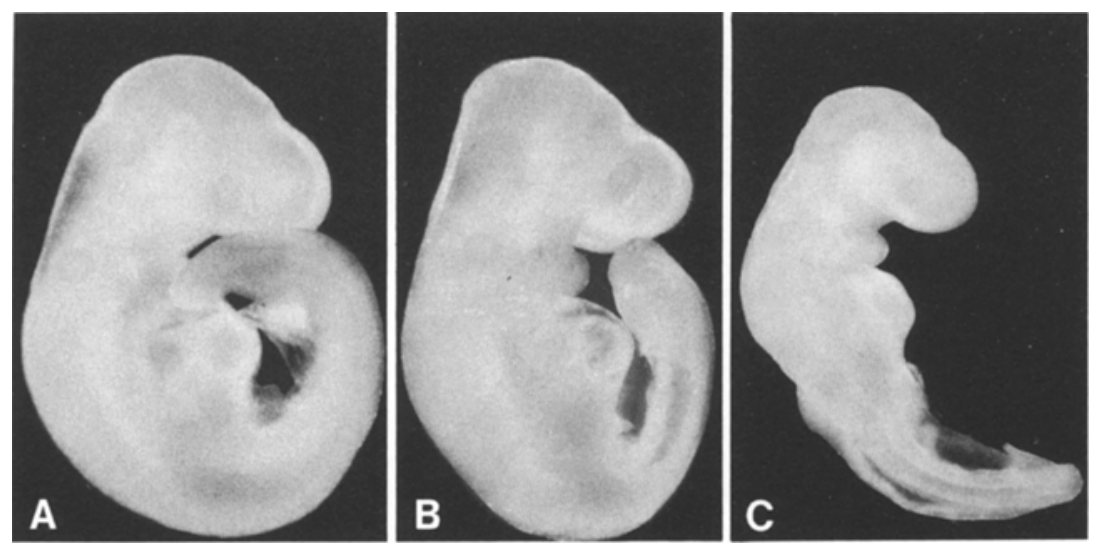

Fig. 1A-C. Rat embryos cultured at $50 \mathrm{mmol} / \mathrm{l}$ glucose showing no malformation yielding malformational score $0(\mathbf{A})$, a minor malformation yielding malformational score 1 (B) and a major malformation yielding malformational score 10 (C). Superoxide dismutase was added to the culture medium (A), catalase to the culture medium $(\mathbf{B})$ and no addition was made to the culture medium (C). $\times 16$ 
tiometric recorder. The maximum light intensity was reached in 12 min and remained essentially constant for several min. The activity of SOD causing a $50 \%$ inhibition of the chemiluminescence was defined as 0.01 unit. This corresponds to $4.2 \mathrm{ng}$ of SOD from bovine erythrocytes. Since the present method is approximately 100 times more sensitive than the original method for SOD determination by McCord and Fridovich [24], this definition would make results obtained by the two methods comparable. It should, however, be noted that the high $\mathrm{pH}$ currently used may affect the activity of various SOD isoenzymes differently $[25,26]$.

Catalase. The activity of CAT was measured by a sensitive spectrophotometric method described recently [27]. This method utilizes the peroxidatic function of CAT for determination of the enzyme activity by the production of formaldehyde from methanol. Samples of tissue homogenates, blanks or formaldehyde standards were incubated in duplicate with $5.9 \mathrm{~mol} / \mathrm{l}$ methanol and $4.2 \mathrm{mmol} / \mathrm{l} \mathrm{H}_{2} \mathrm{O}_{2}$ in a $250 \mathrm{mmol} / 1 \mathrm{KH}_{2} \mathrm{PO}_{4}-\mathrm{NaOH}$ buffer, $\mathrm{pH} 7.0$, for $20 \mathrm{~min}$ at room temperature $\left(20^{\circ} \mathrm{C}\right)$. After termination of the enzymatic reaction with a concentrated $\mathrm{KOH}$ solution, a second incubation with purpald (4amino-3-hydrazino-5-mercapto-1,2,4-triazole) was performed for $10 \mathrm{~min}$ at $20^{\circ} \mathrm{C}$. To obtain a coloured compound, the product of the reaction between formaldehyde and purpald was oxidized by $\mathrm{KIO}_{4}$. The absorbance was measured at $550 \mathrm{~nm}$ in a Beckman DU-65 spectrophotometer (Beckman Instruments, Fullerton, Calif., USA).

Glutathione peroxidase. An enzymatic cycling method, initially described by Paglia and Valentine [28], was used for measurements of the activity of GPX. After mixing of $75-\mu 1$ portions of homogenates or blanks with $200 \mu$ of a $250 \mathrm{mmol} / 1 \mathrm{KH}_{2} \mathrm{PO}_{4}-\mathrm{NaOH}$ buffer, $\mathrm{pH} 7.0$, in polystyrene semi-micro cuvettes, the various components of the assay system were added from stock solutions in phosphate buffer. In a total volume of $500 \mu \mathrm{l}$ the final concentration was $4 \mathrm{mmol} / \mathrm{l}$ of GSH (reduced glutathione), $8.5 \mathrm{mg} / \mathrm{l}$ of glutathione reductase (E.C. 1.6.4.2), $1 \mathrm{mmol} / \mathrm{I} \mathrm{NaN}_{\hat{\jmath}}$ and $1 \mathrm{mmol} / \mathrm{l}$ of EDTA. The cuvettes were incubated in duplicate at $37^{\circ} \mathrm{C}$ for $10 \mathrm{~min}$. By this incubation with GSH inactivated GPX could be regenerated. To give a final concentration of $0.3 \mathrm{mmol} / \mathrm{l}, 50 \mu \mathrm{l}$ of a NADPH (reduced $\beta$-nicotinamide adenine dinucleotide phosphate) solution in $10 \%(\mathrm{w} / \mathrm{v})$ sodium hydrogen carbonate $\left(37^{\circ} \mathrm{C}\right.$ ) was added to each cuvette. The changes in absorbance due to oxidation of NADPH were measured at $340 \mathrm{~nm}$ in a Zeiss PMQ II spectrophotometer (Carl Zeiss, Oberkochen, FRG) equipped with a thermostat set at $37^{\circ} \mathrm{C}$ and a potentiometric recorder. The oxidation of NADPH in the absence of hydroperoxide was recorded for $2 \mathrm{~min}$. Next, $50 \mathrm{\mu l}$ of a solution of $\mathrm{H}_{2} \mathrm{O}_{2}$ in phosphate buffer $\left(37^{\circ} \mathrm{C}\right)$ was added to give a final concentra- tion of $0.1 \mathrm{mmol} / \mathrm{l}$. An organic hydroperoxide was not used, since such a substrate would be metabolized by glutathione S-transferases possibly present in the homogenates. Catalase activities were blocked by the presence of azide. The enzymatic cycling reaction gave a linear decrease in NADPH concentration for up to $10 \mathrm{~min}$. The activity of GPX was determined by the hydroperoxide-specific oxidation of NADPH, and was calculated using a molar absorption coefficient for NADPH of $6200 \mathrm{I} \cdot \mathrm{mol}^{-1} \cdot \mathrm{cm}^{-1}[29]$.

\section{Chemicals}

Sterile solution of $0.9 \%$ (w/v) NaCl was from Baxter (Deerfield, Ill., USA) and sterile $1.67 \mathrm{~mol} / \mathrm{l} \mathrm{D}$-glucose from Kabi Vitrum (Stockholm, Sweden). Sodium benzyl penicillinate and streptomycin in solution for tissue culture was purchased from Flow Laboratories (Irvine, UK). Citiolone (N-acetyl-DL-homocysteine thiolactone), superoxide dismutase (E.C. 1.15.1.1) from bovine erythrocytes, glutathione peroxidase (E.C. 1.11.1.9) from bovine erythrocytes, xanthine and DNA, sodium salt from salmon testes, were from Sigma Chernical Co. (St. Louis, Mo., USA). Bovine serum albumin, fraction $V$, was purchased from Miles Scientific (Naperville, Ill., USA) and luminol (5-amino-2,3-dihydro-1,4-phthalazinedione), purpald (4-amino-3-hydrazino-5-mercapto-1,2,4-triazole) and 3,5diaminobenzoic acid dihydrochloride from Aldrich-Chemie (Steinheim, FRG). Catalase (E.C. 1.11.1.6) from beef liver, xanthine oxidase (E.C. 1.1.3.22) from cow's milk, glutathione reductase (E.C. 1.6.4.2) from yeast, GSH (reduced glutathione) and NADPH (reduced $\beta$ - nicotinamide adenine dinucleotide phosphate, tetrasodium salt) were obtained from Boehringer Mannheim (Mannheim, FRG). All other chemicals of analytical grade, including Folin-Ciocalteu's phenol reagent, were from E. Merck (Darmstadt, FRG).

\section{Statistical analysis}

Statistical inferences were based on Student's two-tailed $t$-test for mean values or $\chi^{2}$-statistics with Yates' correction for proportions of normal embryos and embryos with minor and major malformations [30].

\section{Results}

When the rat embryos were cultured in $10 \mathrm{mmol} / \mathrm{lglucose}$ (10G) for $48 \mathrm{~h}$, they exhibited a development which reflected the in vivo conditions. At the end of the culture

Table 1. Effects of free oxygen radical scavenging enzymes on morphology of cultured rat embryos

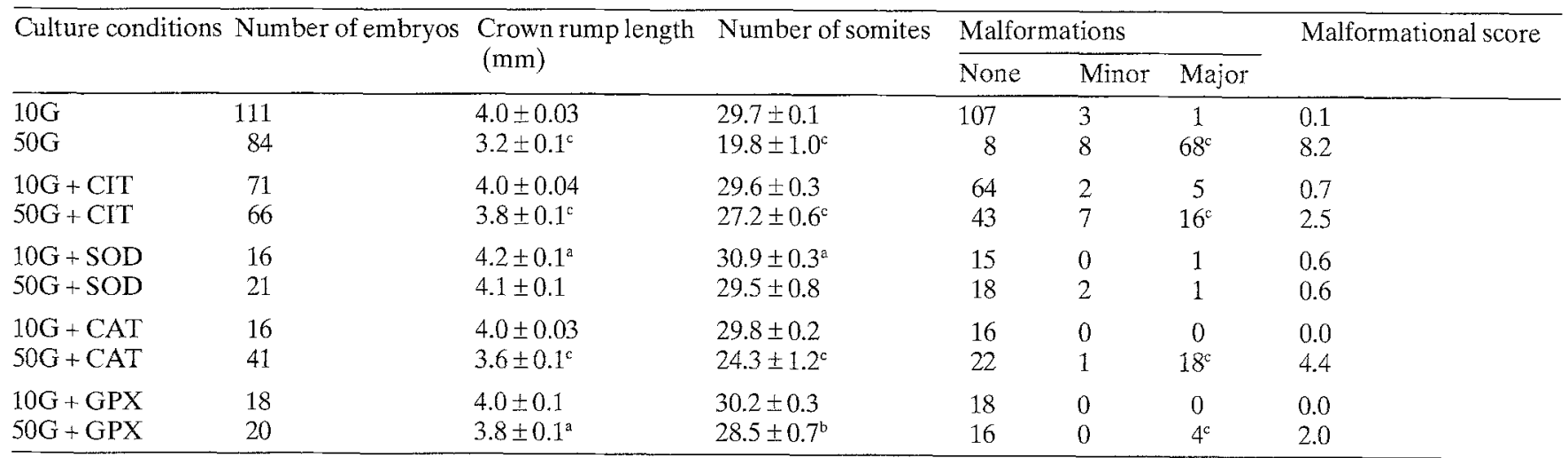

The rat embryos were cultured at either $10 \mathrm{mmol} / \mathrm{l}$ (10G) or $50 \mathrm{mmol} / \mathrm{l}(50 \mathrm{G})$ glucose. Citiolone (CIT), superoxide dismutase (SOD), catalase (CAT) and glutathione peroxidase (GPX) were added to culture media as indicated. For crown rump length and number of somites results are given as mean values \pm SEM, and differences to embryos cultured at $10 \mathrm{G}$ are evaluated by Student's $t$-test. For malformations results are given as the number of embryos in each category, and differences to culture at $10 \mathrm{G}$ are evaluated by $\chi^{2}$-statistics with Yates' correction. Malformational score is calculated as described in the text.

${ }^{\mathrm{a}} p<0.05 ;^{\mathrm{b}} p<0.01 ;^{\mathrm{c}} p<0.001$ 
Table 2. Effects of free oxygen radical scavenging enzymes on growth of cultured rat embryos

\begin{tabular}{lllll}
\hline $\begin{array}{l}\text { Culture con- } \\
\text { ditions }\end{array}$ & $\begin{array}{l}\text { Number of } \\
\text { embryos }\end{array}$ & $\begin{array}{l}\text { Protein con- } \\
\text { tent }(\mu \mathrm{g})\end{array}$ & $\begin{array}{l}\text { DNA con- } \\
\text { tent }(\mu \mathrm{g})\end{array}$ & $\begin{array}{l}\text { Protein/DNA } \\
(\mu \mathrm{g} / \mu \mathrm{g})\end{array}$ \\
\hline $10 \mathrm{G}$ & 111 & $303 \pm 7$ & $23.6 \pm 0.6$ & $13.4 \pm 0.3$ \\
$50 \mathrm{G}$ & 84 & $242 \pm 9^{\mathrm{c}}$ & $16.5 \pm 0.7^{\mathrm{c}}$ & $15.2 \pm 0.4^{\mathrm{c}}$ \\
$10 \mathrm{G}+\mathrm{CIT}$ & 71 & $322 \pm 11$ & $22.8 \pm 0.7$ & $14.4 \pm 0.3^{\mathrm{a}}$ \\
$50 \mathrm{G}+\mathrm{CIT}$ & 66 & $299 \pm 11$ & $20.8 \pm 0.8^{\mathrm{b}}$ & $14.8 \pm 0.4^{\mathrm{b}}$ \\
$10 \mathrm{G}+\mathrm{SOD}$ & 16 & $300 \pm 12$ & $25.8 \pm 0.9$ & $11.8 \pm 0.6^{\mathrm{a}}$ \\
$50 \mathrm{G}+\mathrm{SOD}$ & 21 & $304 \pm 8$ & $20.6 \pm 1.1$ & $15.1 \pm 0.4^{\mathrm{a}}$ \\
$10 \mathrm{G}+\mathrm{CAT}$ & 16 & $336 \pm 22$ & $24.0 \pm 1.2$ & $14.1 \pm 0.8$ \\
$50 \mathrm{G}+\mathrm{CAT}$ & 41 & $297 \pm 13$ & $19.5 \pm 0.9^{\mathrm{c}}$ & $16.0 \pm 0.7^{\mathrm{c}}$ \\
$10 \mathrm{G}+\mathrm{GPX}$ & 18 & $277 \pm 12$ & $20.3 \pm 1.3^{\mathrm{a}}$ & $14.3 \pm 0.8$ \\
$50 \mathrm{G}+\mathrm{GPX}$ & 20 & $272 \pm 8^{\mathrm{a}}$ & $20.8 \pm 0.9^{\mathrm{a}}$ & $13.3 \pm 0.4$ \\
\hline
\end{tabular}

The rat embryos were cultured at either $10 \mathrm{mmol} / \mathrm{l}$ (10G) or $50 \mathrm{mmol} / \mathrm{l}(50 \mathrm{G})$ glucose. Citiolone (ClT), superoxide dismutase (SOD), catalase (CAT) and glutathione peroxidase (GPX) were added to culture media as indicated. Results are given as mean values \pm SEM, and differences to embryos cultured at $10 \mathrm{G}$ are evaluated by Student's $t$-test. ${ }^{\mathrm{a}} p<0.05,{ }^{\mathrm{b}} p<0.01 ;{ }^{\mathrm{c}} p<0.001$

period, corresponding to a gestational age of 11.7 days, the embryos had a mean crown rump length of $4 \mathrm{~mm}$ and had developed an average of 30 somites. After culture at $10 \mathrm{G}$ about $3 \%$ of the embryos showed some kind of malformation yielding a malformational score of 0.1 . This is similar to that normally found for rats in vivo [11]. An increase in ambient glucose concentration to $50 \mathrm{mmol} / \mathrm{l}$ (50G) caused a decrease of $20 \%$ in crown rump length and of $33 \%$ in the number of somites (Table 1). The number of embryonic malformations was much higher at $50 \mathrm{G}$ than at $10 \mathrm{G}$. Thus, in culture with $50 \mathrm{G} 10 \%$ of the embryos showed minor malformations and $81 \%$ major malformations, which yielded a malformational score of 8.2 (Table 1). Most embryos with a major malformation showed either severe malrotation or an abnormally open neural tube. Compared to $10 \mathrm{G}$, culture in $50 \mathrm{G}$ resulted in both a lower embryonic content of protein and DNA (Table 2). This reflected the decreased growth of the embryos cultured in 50G. The endogenous activity of SOD was significantly greater in embryos and membranes exposed to $50 \mathrm{G}$ than in those subjected to $10 \mathrm{G}$ (Fig.2; $p<0.05)$. However, this effect was not found for the endogenous activities of CAT and GPX (Figs. 3 and 4).

Addition of $0.5 \mathrm{mmol} / \mathrm{l} \mathrm{CIT}$ to the $10 \mathrm{G}$ cultures did not affect the crown rump length or the number of somites of the embryos (Table 1). At $50 \mathrm{G}$ the addition of CIT partly normalized the growth and development of the embryos. Thus, both the crown rump length and somite number were increased compared with culture in $50 \mathrm{G}$ alone $(p<0.001)$, and the malformational score was increased in comparison to culture in $10 \mathrm{G}$, but decreased compared to $50 \mathrm{G}$ culture. Addition of CIT to the $10 \mathrm{G}$ cultures did not change the protein or DNA content of the embryos, but it caused a slight increase in protein/DNA ratio (Table 2). Addition of CIT to $50 \mathrm{G}$ cultures gave a intermediate value for DNA, which differed from both $10 \mathrm{G}$ and $50 \mathrm{G}$ values $(p<0.01)$, but normalized the protein content of the embryos and slightly increased their protein/DNA ratio (Table 2). CIT significantly in-

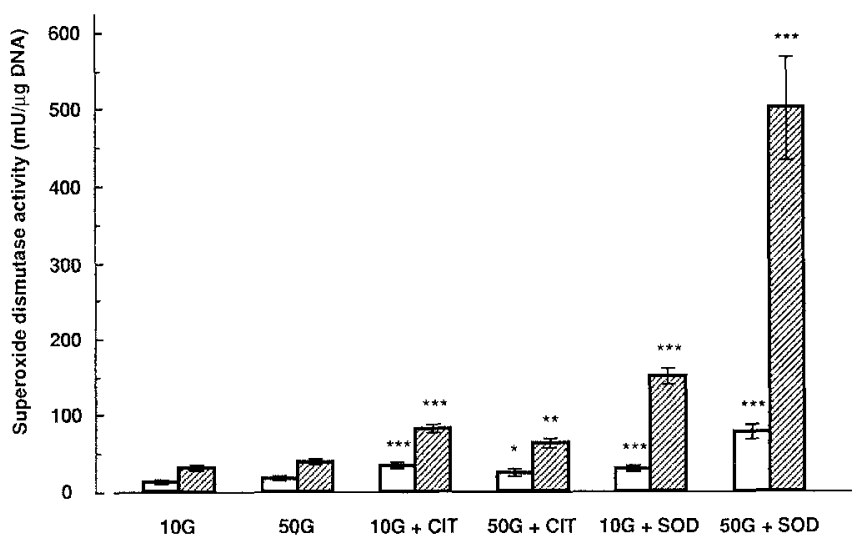

Fig.2. Activity of superoxide dismutase (SOD) in embryos ( $\square$ ) and membranes ( ) of rat conceptuses cultured at either $10 \mathrm{mmol} / \mathrm{l}$ (10G) or $50 \mathrm{mmol} / \mathrm{l}(50 \mathrm{G})$ glucose. Citiolone (CIT) and SOD were added to culture media as indicated. Results are given as mean values \pm SEM of $8-12$ observations, and differences to culture without additions are evaluated by Student's $t$-test. ${ }^{*} p<0.05$;

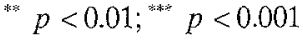

creased the activity of SOD both in the embryos and membranes (Fig. 2), whereas the drug had no effect on the activities of CAT (Fig. 3) or GPX (Fig.4). The induction of SOD activity by CIT was not dependent on the glucose concentration of the culture medium. In separate experiments it was also shown that $0.5 \mathrm{mmol} / \mathrm{l}$ CIT did not interfere with the determinations of enzyme activities (data not shown).

None of the three different scavenging enzymes influenced the embryonic development at $10 \mathrm{G}$ except for SOD that slightly increased the crown rump length and somite number of the embryos (Table 1). At $50 \mathrm{G}$ the addition of SOD to the cultures produced a complete normalization of both the crown rump length, the number of somites and the morphology of the embryos resulting in a malformational score of 0.6 (Table 1 ). All types of malformations observed were affected similarly. Protein and DNA content of the embryos in the SOD-supplemented $50 \mathrm{G}$ cultures were not different from that of the embryos in $10 \mathrm{G}$ cultures, but the protein/DNA ratio was slightly increased (Table 2).

Addition of CAT or GPX to the $50 \mathrm{G}$ cultures did not result in full normalization of embryonic growth and development, when compared to $10 \mathrm{G}$ cultures. The values for crown rump length, number of somites and malformations were significantly different from the values for embryos in $10 \mathrm{G}$ cultures (Table 1). However, the supplementation of CAT and GPX improved the embryonic development. For instance, in CAT-supplemented $50 \mathrm{G}$ cultures the crown rump length and the number of somites were increased $(p<0.01)$ and the proportion of malformed embryos was decreased $(p<0.001)$ in comparison to cultures in $50 \mathrm{G}$ alone. Similarly, the addition of GPX to $50 \mathrm{G}$ culture resulted in an improved crown rump length, somite number and proportion of malformed embryos, when compared to $50 \mathrm{G}$ culture without the addition of any enzyme $(p<0.001)$. Similar differences were noted with regard to the protein and DNA content of embryos cultured with supplementation of CAT or GPX. Thus, 


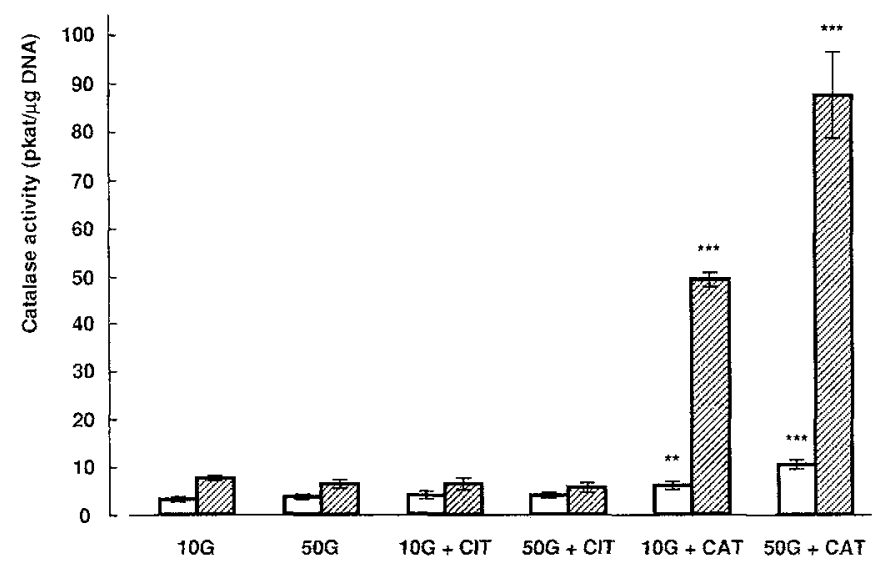

Fig. 3. Activity of catalase (CAT) in embryos $(\square)$ and membranes (*) of rat conceptuses cultured at either $10 \mathrm{mmol} / \mathrm{l}(10 \mathrm{G})$ or $50 \mathrm{mmol} / 1(50 \mathrm{G})$ glucose. Citiolone (CIT) and CAT were added to culture media as indicated. Results are given as mean values \pm SEM of $6-8$ observations, and differences to culture without additions are evaluated by Student's $t$-test. ${ }^{* * *} p<0.01 ;^{* * * *} p<0.001$

addition of CAT to $10 \mathrm{G}$ cultures did not change any of the growth parameters (Table 2), and addition of GPX to 10G cultures yielded a slightly lowered DNA value but did not change the protein content or the protein/DNA ratio of the embryos. Addition of CAT or GPX to 50G cultures, however, did not protect the embryos from the decrease in protein and DNA content caused by the high glucose concentration (Table 2).

The addition of enzymes to the culture medium significantly increased the enzyme activities both in the embryos proper and their membranes (Figs. 2-4). The enzymatic activities were 10-100 times higher in the membranes than in the embryos. It should also be noted that the accumulation of SOD and CAT in embryos and membranes was greater at $50 \mathrm{G}$ than at $10 \mathrm{G}(p<0.001)$. However, the glucose concentration of the culture medium had apparently no effect on the uptake of GPX in the embryos or membranes.

\section{Discussion}

Several changes in the metabolic environment of the embryos caused by maternal diabetes have been associated with disturbed embryonic morphogenesis in diabetic pregnancy. Thus, both a high concentration of glucose [9], a low glucose concentration [31] and a high concentration of $\beta$-hydroxybutyrate [32] have been shown to be teratogenic in vitro. Furthermore, various consequences of increased ambient glucose concentration have been suggested to play a role in the disturbed embryogenesis, such as arachidonic acid depletion $[33,34]$, hyperaccumulation of sorbitol [35-38], deficiency of myo-inositol [36, 37, 3941] or alterations in trace metal concentrations of the offspring [42, 43]. Mannose [44, 45] and somatomedin inhibitors from serum of diabetic rats [46] also cause embryonic malformations. In addition, the genetic background of the diabetic mother and her fetus have been shown to be associated with the dysmorphogenesis of diabetic pregnancy

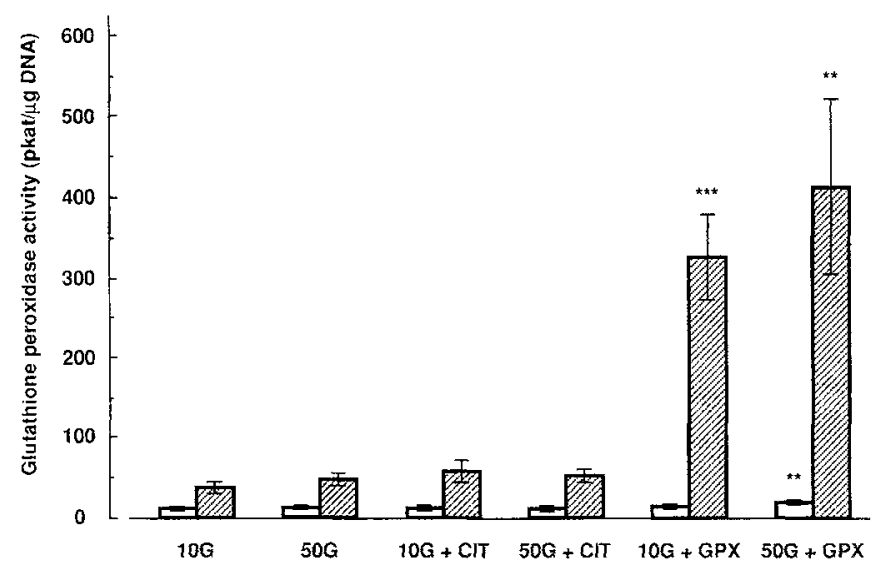

Fig.4. Activity of glutathione peroxidase (GPX) in embryos ( $\square$ ) and membranes ( $\square$ ) of rat conceptuses cultured at either $10 \mathrm{mmol} / \mathrm{l}(10 \mathrm{G})$ or $50 \mathrm{mmol} / \mathrm{l}(50 \mathrm{G})$ glucose. Citiolone (CIT) and GPX were added to culture media as indicated. Results are given as mean values \pm SEM of 7-10 observations, and differences to culture without additions are evaluated by Student's $t$-test. ${ }^{* * 1} p<0.01$; ::: $p<0.001$

[11]. A general consensus emerging from the previous reports is that none of the proposed processes seem to offer a complete explanation for the dysmorphogenesis in diabetic pregnancy. This may be because the teratological mechanism is multifactorial and most of the studies have not allowed evaluation of possible synergistic actions between different agents, or that the most important factor(s) have not yet been identified.

In the present study the novel approach was to investigate the possible involvement of free oxygen radicals in the glucose-induced embryonic dysmorphogenesis. The results showed that it is possible to achieve normalized embryonic in vitro development, despite exposure to teratogenic and growth retarding concentrations of glucose, by increasing the free oxygen radical scavenging capacity of the conceptus. These findings suggest that free oxygen radicals are involved in the glucose-dependent teratogenic process.

How would glucose influence the occurrence of free oxygen radicals in the embryo? There seem to be two main alternatives, the glucose-rich environment may either cause a decreased radical scavenging capacity or an increased production of free oxygen radicals in the conceptus. The first possibility may be supported by findings suggesting decreased activity of SOD or GPX and decreased concentrations of vitamin $\mathrm{E}$ or GSH in various organs of diabetic humans and animals [6]. However, there are no published measurements of the activities of free oxygen radical scavenging enzymes in embryos except for those in the present study, which showed unchanged activities of CAT and GPX and a slightly increased general activity of SOD in the conceptuses cultured in a high glucose concentration. The other possibility, an increased net production of free oxygen radicals in the glucose-rich milieu, therefore, seems more likely. It should, however, be noted that three different SOD isoenzymes have been described, namely cytosolic $\mathrm{CuZn-}$ SOD [24], mitochondrial MnSOD [47] and extracellular SOD [26]. It is presently not known how the metabolic dis- 
turbances in diabetes may affect the activities of these isoenzymes.

The generation of the free oxygen radicals at high glucose concentrations may be promoted in several ways. A mechanism has been described where non-enzymatically glycated proteins may induce free oxygen radical generation $[7,48]$. Such a mechanism would demand preformed glycated proteins. The relatively short duration of the embryo culture, however, makes the presence of significant amounts of such glycated proteins less likely. Another, and more probable, site of origin of free oxygen radicals would be the mitochondria of the conceptus, where the increased load of glucose would cause an increased flow through the electron transport chain. In concert with this notion is the report of a distinct teratogenic effect of culture at increased oxygen pressure [49], which would increase the endogenous production of free oxygen radicals. At a high oxygen pressure the mitochondria of the neuroectoderm are also morphologically altered with an increased number of cristae, which indicate an enhanced function [49]. This is of particular interest, since the mitochondria are just about mature enough to handle oxygen at this early stage of embryogenesis and the embryos are changing from anaerobic to aerobic metabolism during the culture period [50]. This implies that the amount of oxygen metabolized is low, but may also imply that the defence capacity against free oxygen radicals is limited at this stage of embryonic development. In this context, the demonstration of younger embryos as more vulnerable to a glucose challenge may be of importance [10], since younger embryos may have less well developed defence mechanisms compared to older embryos. The teratogenic period for congenital malformations in two different models for diabetic pregnancy also occurs at a stage when the embryos are young, around gestational days $6-10[51,52]$, and the embryonic oxidative systems may be immature.

The primary effect of increased activities of free oxygen radicals would be an enhanced lipid peroxidation, but also direct effects on DNA may be considered. In a previous study it was not possible, however, to demonstrate DNA damage, since culture of embryos in high glucose concentrations did not induce increased DNA repair activity [53]. The major products of lipid peroxidation, the hydroperoxides, are known stimulants of prostaglandin biosynthesis but inhibit the production of prostacyclin [54], an imbalance which may have deleterious effects on the embryo. The previous findings of a beneficial effect of arachidonic acid [33,34], prostaglandin $E_{2}$ and $F_{2} \alpha$ and prostacyclin [39] on embryos in a diabetic environment may also relate to this notion, since the supplementation of these substances may correct a possible imbalance in prostaglandin biosynthesis. Likewise, the finding of a beneficial effect of myo-inositol supplementation to high-glucose culture $[39,40]$, compensating for a decreased embryonic uptake of this hexose [41], may be explained by a restored production of phosphatidylinositol and a subsequent normalization of phospholipase $\mathrm{A}_{2}$ activity [55].

In conclusion the present study suggests that high glucose concentrations cause embryonic dysmorphogenesis in vitro by generation of free oxygen radicals. An en- hanced formation of free oxygen radicals in the embryo may directly relate to the increased risk of congenital malformations in diabetic pregnancy. If such a relationship is also present in human diabetic gestation it would have therapeutic implications.

Acknowledgements. The authors are grateful to Ms. P. Wentzel for expert technical assistance. This investigation was supported by the Swedish Medical Research Council (12X-7475 and 12X-6538), the "Expressen" Prenatal Research Foundation, the Swedish Diabetes Association, the Nordisk Insulin Foundation Committee, the Swedish Hoechst Diabetes Fund and the Family Ernfors Fund.

\section{References}

1. Kucera J (1971) Rate and type of congenital anomalies among offspring of diabetic women. J Reprod Med 7:61-70

2. Pedersen J (1977) The pregnant diabetic and her newborn. Problems and management. 2nd edn. Munksgaard, Copenhagen

3. Freinkel N (1980) Of pregnancy and progeny. Diabetes 29:10231035

4. Mills $\mathbf{J}$ (1982) Malformations in infants of diabetic mothers. Teratology 25: 385-394

5. Jennings PE, Jones AF, Florkowski CM, Lunec J, Barnett AH (1987) Increased diene conjugates in diabetic subjects with microangiopathy. Diabetic Med 4: 452-456

6. Oberley LW (1988) Free radicals and diabetes. Free Radical Biol Med 5: 113-124

7. Gillery P, Monboisse J-C, Maquart F-X, Borel J-P (1989) Does oxygen free radical increased formation explain long term complications of diabetes mellitus? Med Hypotheses 29:47-50

8. Jenkinson PC, Anderson D, Gangolli SD (1986) Malformations induced in cultured rat embryos by enzymically generated active oxygen species. Teratog Carcinog Mutag 6: 547-554

9. Cockroft DL, Coppola PT (1977) Teratogenic effects of excess glucose on head-fold rat embryos in culture. Teratology 16: 141146

10. Sadler TW (1980) Effects of maternal diabetes on early embryogenesis: II. Hyperglycemia-induced exencephaly. Teratology $21: 349-356$

11. Eriksson UJ (1988) Importance of genetic predisposition and maternal environment for the occurrence of congenital malformations in offspring of diabetic rats. Teratology 37: 365374

12. Totaro EA, Pisanti FA, Liberatori E (1985) Possible interrelations of acetyl-homocyteine-thiolactone in mechanisms of lipofuscinogenesis. Res Commun Chem Pathol Pharmacol 47: 415426

13. Papaccio G, Pisanti FA, Frascatore S (1986) Acetyl-homocysteine-thiolactone-induced increase of superoxide dismutase counteracts the effects of subdiabetogenic doses of streptozocin. Diabetes 35: 470-474

14. Eriksson UJ, Borg LAH (1990) Free radical scavenging enzymes protect against glucose-induced embryonic malformations in vitro. Diabetologia 33:139 (Abstract)

15. Eriksson UJ, Dahlström E, Larsson KS, Hellerström C (1982) Increased incidence of congenital malformations in the offspring of diabetic rats and their prevention by maternal insulin therapy. Diabetes 31:1-6

16. New DAT (1978) Whole-embryo culture and the study of mammalian embryos during organogenesis. Biol Rev 53: 81-122

17. Steele CE, New DAT (1974) Serum variants causing the formation of double hearts and other abnormalities in explanted rat embryos. J Embryol Exp Morphol 31: 707-719

18. New DAT, Coppola PT, Cockroft DL (1976) Improved development of head-fold rat embryos in culture resulting from low oxygen and modification of culture serum. J Reprod Fertil 48: 219222 
19. Lowry OH, Rosebrough NJ, Farr AL, Randall RJ (1951) Protein measurement with the folin phenol reagent. J Biol Chem 193: 265-275

20. Kissane JM, Robins E (1958) The fluorometric measurement of deoxyribonucleic acid in animal tissues with special reference to the central nervous system. J Biol Chem 233: 184-188

21. Hinegardner RT (1971) An improved fluorometric assay for DNA. Anal Biochem 39: 197-201

22. Puget K, Michelson AM (1974) Iron containing superoxide dismutases from luminous bacteria. Biochimie 56: 1255-1267

23. Bensinger RE, Johnson CM (1981) Luminol assay for superoxide dismutase. Anal Biochem 116: 142-145

24. McCord JM, Fridovich I (1969) Superoxide dismutase. An enzymic function for erythrocuprein (hemocuprein). J Biol Chem 244: 6049-6055

25. Forman HJ, Fridovich I (1973) Superoxide dismutase: a comparison of rate constants. Arch Biochem Biophys 158: 396400

26. Marklund SL (1982) Human copper-containing superoxide dismutase of high molecular weight. Proc Natl Acad Sci USA 79: 7634-7638

27. Johansson LH, Borg LAH (1988) A spectrophotometric method for determination of catalase activity in small tissue samples. Anal Biochem 174: 331-336

28. Paglia DE, Valentine WN (1967) Studies on the quantitative and qualitative characterization of erythrocyte glutathione peroxidase. J Lab Clin Med 70: 158-169

29. Horecker BL, Kornberg A (1948) The extinction coefficients of the reduced band of pyridine nucleotides. J Biol Chem 175:385390

30. Ostle B (1963) Statistics in research. 2nd edn. lowa State University Press, Ames

31. Akazawa S, Akazawa M, Hashimoto M, Yamaguchi Y, Kuriya N, Toyama K, Ueda Y, Nakanishi T, Mori T, Miyake S, Nagataki S (1987) Effects of hypoglycaemia on early embryogenesis in rat embryo organ culture. Diabetologia 30: 791-796

32. Horton WE Jr, Sadler TW (1983) Effects of maternal diabetes on early embryogenesis. Alterations in morphogenesis produced by the ketone body, B-hydroxybutyrate. Diabetes 32:610-616

33. Goldman AS, Baker L, Piddington R, Marx B, Herold R, Egler J (1985) Hyperglycemia-induced teratogenesis is mediated by a functional deficiency of arachidonic acid. Proc Natl Acad Sci USA 82: 8227-8231

34. Pinter E, Reece EA, Leranth CZ, Garcia-Segura M, Hobbins JC, Mahoney MJ, Naftolin F (1986) Arachidonic acid prevents hyperglycemia-associated yolk sac damage and embryopathy. Am J Obstet Gynecol 155: 691-702

35. Eriksson UJ, Naeser P, Brolin SE (1986) Increased accumulation of sorbitol in offspring of manifest diabetic rats. Diabetes 35 : 1356-1363

36. Hod M, Star S, Passonneau JV, Unterman TG, Freinkel N (1986) Effect of hyperglycemia on sorbitol and myo-inositol content of cultured rat conceptus: failure of aldose reductase inhibitors to modify myo-inositol depletion and dysmorphogenesis. Biochem Biophys Res Commun 140: 974-980

37. Sussman I, Matschinsky FM (1988) Diabetes affects sorbitol and myo-inositol levels of neuroectodermal tissue during embryogenesis in rat. Diabetes 37: 974-981

38. Eriksson UJ, Naeser P, Brolin SE (1989) Influence of sorbitol accumulation on growth and development of embryos cultured in elevated levels of glucose and fructose. Diabetes Res Clin Exp 11:27-32

39. Baker L, Piddington R, Goldman A, Egler J, Moehring J (1990) Myo-inositol and prostaglandins reverse the glucose inhibition of neural tube fusion in cultured mouse embryos. Diabetologia 33: 593-596

40. Hashimoto M, Akazawa S, Akazawa M, Akashi M, Yamamoto H. Maeda Y, Yamaguchi Y, Yamasaki H, Tahara D, Nakanishi T, Nagataki S (1990) Effects of hyperglycemia on sorbitol and myoinositol contents of cultured embryos: treatment with aldose reductase inhibitor and myo-inositol supplementation. Diabetologia 33: 597-602

41. Weigensberg MJ, Garcia-Palmer F-J, Freinkel N (1990) Uptake of myo-inositol by early-somite rat conceptus. Transport kinetics and effects of hyperglycemia. Diabetes 39:575-582

42. Eriksson UJ (1984) Diabetes in pregnancy: retarded fetal growth, congenital malformations and feto-maternal concentrations of zinc, copper and manganese in the rat. J Nutr 114: 477-486

43. Uriu-Hare JY, Stern JS, Reaven GM, Keen CL (1985) The effect of maternal diabetes on trace element status and fetal development in the rat. Diabetes 34: 1031-1040

44. Freinkel N, Lewis NJ, Akazawa S, Roth S, Gorman L (1984) The honeybee syndrome - implications of the teratogenicity of mannose in rat embryo culture. N Engl J Med 313: 96-101

45. Buchanan TA, Freinkel N, Lewis NJ, Metzger BE, Akazawa S (1985) Fuel-mediated teratogenesis. Use of D-mannose to modify organogenesis in the rat embryo in vivo. J Clin Invest 75: 1927-1934

46. Sadler TW, Phillips LS, Balkan W, Goldstein S (1986) Somatomedin inhibitors from diabetic rat serum alter growth and development of mouse embryos in culture. Diabetes 35: 861-865

47. Weisiger RA, Fridovich I (1973) Superoxide dismutase. Organelle specificity. J Biol Chem 248:3582-3592

48. Hunt JV, Dean RT, Wolff SP (1988) Hydroxyl radical production and autoxidative glycosylation. Biochem $\mathrm{J}$ 256:205-212

49. Morriss GM, New DAT (1979) Effect of oxygen concentration on morphogenesis of cranial neural folds and neural crest in cultured rat embryos. J Embryol Exp Morphol 54: 17-35

50. Shepard TH, Tanimura T, Robkin MA (1970) Energy metabolism in early mammalian embryos. Dev Biol 4: [Suppl] 42-58

51. Eriksson RSM, Thunberg L, Eriksson UJ (1989) Effects of interrupted insulin treatment on fetal outcome of pregnant diabetic rats. Diabetes 38: 764-772

52. Eriksson UJ, Bone AJ, Turnbull DM, Baird JD (1989) Timed interruption of insulin therapy in diabetic BB/E rat pregnancy: effects on maternal metabolism and fetal outcome. Acta Endocrinol (Copenh) 120:800-810

53. Eriksson UJ, Borg LAH (1988) Does hyperglycemia in vitro cause maldevelopment of embryos by deranging their metabolism of DNA? In: Shafrir E, Renold AE (eds) Frontiers in diabetic research. Lessons from animal diabetes II. John Libbey, London Paris, pp 418-422

54. Warso MA, Lands WEM (1983) Lipid peroxidation in relation to prostacyclin and thromboxane physiology and pathophysiology. Br Med Bull 39: 277-280

55. Lapetina EG (1982) Regulation of arachidonic acid production: role of phospholipases C and $\mathrm{A}_{2}$. Trends Pharmacol Sci 3: 115118

Received: 8 November 1990

and in revised form: 17 January 1991

Dr. U.J.Eriksson

Department of Medical Cell Biology

University of Uppsala

Box 571

S-751 23 Uppsala

Sweden 